Sociohistórica, $\mathrm{n}^{\circ}$ 41, e053, 1er. Semestre de 2018. ISSN

1852-1606 Universidad Nacional de La Plata.

Facultad de Humanidades y Ciencias de la Educación.

Centro de Investigaciones Socio Históricas

\title{
Las representaciones del gaucho en los engranajes de la nación argentina.
}

\section{Reseña de: Casas, Matías Emiliano (2017). Las metamorfosis del gaucho. Círculos criollos, tradicionalistas y política en la provincia de Bs As 1930-1960. CABA: PROMETEO, págs. 300}

\section{Leandro Nicolás Pankonin*}

* Instituto de Desarrollo Humano (IDH) - Universidad Nacional de General Sarmiento - CONICET, Argentina

leandro_pankonin@yahoo.com.ar

Cita recomendada: Pankonin, L. (2018). Las representaciones del gaucho en los engranajes de la nación argentina. Sociohistorica, 41, e053. https://doi.org/10.24215/18521606e053

Recibido: 18 de febrero de 2018 - Aceptado: 26 de febrero de 2018 - Publicado: 29 de junio de 2018

Esta obra está bajo licencia Creative Commons Atribución-NoComercial-CompartirIgual 4.0 Internacional http:// creativecommons.org/licenses/by-nc-sa/4.0/deed.es_AR 
Las representaciones del gaucho en los engranajes de la nación argentina. Reseña de: Casas, Matías Emiliano (2017). Las metamorfosis del gaucho. Círculos criollos, tradicionalistas y política en la provincia de Bs As 1930-1960. CABA: PROMETEO, págs. 300

\author{
Leandro Nicolás Pankonin \\ Instituto de Desarrollo Humano (IDH) - Universidad Nacional de General \\ Sarmiento (UNGS)/Consejo Nacional de Investigaciones Cientificas y Técnicas \\ (CONICET), Argentina \\ leandro_pankonin@yahoo.com.ar
}

El trabajo al que aquí nos referimos es fruto de la investigación que Matías Emiliano Casas realizó como becario del CONICET a fin de doctorarse en historia por la Universidad Nacional de Tres de Febrero (UNTreF) y la Universidad París Diderot (París 7). Casas muestra en la introducción de Las metamorfosis del gaucho una serie de "episodios" que dan cuenta de la relación del gaucho con la "argentinidad". Si bien dichos episodios pertenecen a la historia reciente de nuestro país y, como tales, se encuentran por fuera de la cronología analizada, el autor los expone como cristalizaciones sumamente "naturalizadas" del principio que reconoce al gaucho como símbolo de la argentinidad. Su trabajo va a consistir en desgranar dicho consenso analizando sobre qué elementos se construyó históricamente ese vínculo. El autor afirma que su trabajo "se empeña en problematizar y analizar la construcción, la circulación y las búsquedas de consenso de las representaciones del gaucho". Y en ese sentido las "metamorfosis a las que remite el título de este libro no se refieren a las transformaciones experimentadas por los gauchos en tanto sujetos característicos de la campaña decimonónica, sino más bien a los desplazamientos y reformulaciones de sus distintas representaciones". El trabajo va a orbitar directamente sobre "las formas, prácticas y simbólicas, en las que fue evocado el gaucho" (p.13). Para construir ese argumento Casas va a tejer una densa red conceptual que enhebra el problema de las representaciones, la identidad, y el problema de la nación y la nacionalidad ligado a los imaginarios.

Este libro se inserta en los debates en torno al problema de la nación y los usos del pasado. Casas logra interpelar las construcciones de sentido en torno al gaucho como arquetipo, a fin de indagar qué nos dicen dichas representaciones sobre la idea de nación, particularmente sobre las formas de pensar la nación y sus pasados en distintas coyunturas. Es decir, que el gaucho, lejos de mantenerse estático y siempre igual a sí mismo, ha sufrido metamorfosis, y, en ese sentido, lo que le interesa al autor es "poner de relieve la utilización de la figura del gaucho -y las reacciones frente a esos usos- para dar cuenta de sus engranajes internos" (p.23). Para tal fin Casas construyó una cronología que comienza en la década del treinta en un contexto en que se exacerbaron las preocupaciones por la identidad nacional, y en el que la figura del gaucho tuvo un rol importante, hasta los albores de la década del sesenta en que el autor identificó un nuevo escenario de reconfiguración de las disputas en torno al gaucho en una coyuntura sumamente distinta a la primera. A medio camino, en 1939, ubicó como punto de quiebre, en lo que concierne a las formas de representar al gaucho en varios sentidos, la sanción de la ley para la provincia de Buenos Aires que oficializó la efeméride del Día de la tradición el 10 de noviembre (natalicio de José Hernández). Por un lado, porque hasta ese momento la reivindicación del gaucho había estado ligada fundamentalmente a la participación civil, y a partir de entonces dicho fenómeno entraría en una etapa distinta con una fuerte intervención 
institucional. Y, por otro lado, porque -en discusión con el diagnostico apocalíptico que realizó Adolfo Prieto con respecto a la decadencia de los centros tradicionalistas en la década del veinte- entiende que a partir de allí, lejos de haberse fijado una representación unívoca del gaucho, éstas se multiplicaron. En ese sentido, la investigación se circunscribe a la provincia de Buenos Aires por ser el escenario de oficialización del gaucho durante la gobernación de Manuel Fresco. El autor muestra el modo en que este reconocimiento en territorio bonaerense tuvo, con el pasar de los años, una onda expansiva hacia todo el territorio nacional, tanto a nivel institucional -desde 1943 se comenzó a celebrar el día de la tradición en todas las escuelas del país, y en 1948 se nacionalizó el día de la tradición por decreto presidencial- como a través de una red de relaciones construida por una diversidad de centros tradicionalistas a lo largo del país con distintos niveles de interacción.

Llegado este punto podemos decir que nos encontramos frente a un problema sumamente difícil de asir. En ese sentido uno de los mayores aciertos del autor es haber asumido una metodología efectiva para desentrañar importantes capas de sentido sobre la cuestión. Los puntos de emergencia de la figura del gaucho y sus formas de representación podrían resultar inabarcables sin nos abocamos a la literatura sobre el tema, dado el enorme volumen y diversidad de producciones que existen. De cualquier forma, el autor dedica el primer capítulo titulado "Genealogía de una trama: de la literatura costumbrista al tradicionalismo" a este problema, ya que entiende que las obras "clásicas" de la literatura gauchesca del siglo XIX han funcionado como el epicentro de buena parte de las formas de representar al gaucho que se resignificaron y reprodujeron en forma posterior.

Casas muestra el modo en que la oficialización del gaucho en 1939 se vio acompañada por la expansión de las experiencias asociativas de grupos tradicionalistas y círculos criollos. Éstos se consolidaron a partir de los años cuarenta, al calor de la nueva efeméride, como ámbitos evocativos de la vida rural y gauchesca. Son justamente estos espacios, los que el autor tomó como objeto de estudio por excelencia para analizar su problema. El investigador asumió la estrategia de trabajar sobre los engranajes internos, las interacciones, que se dieron en casos particulares de centros criollistas y tradicionalistas, a fin de ver cuáles fueron los lazos que se tejieron allí, qué representaciones del gaucho construyeron en cada caso y en cada coyuntura, y en qué medida esas representaciones tuvieron una fuerza centrífuga capaz de propagarse de allí a otros campos sociales. En este sentido, una buena parte del trabajo de Casas consiste en reconstruir las interacciones entre representantes de los centros criollos, de la Iglesia católica, de las Fuerzas Armadas, y miembros de la comunidad educativa, que produjeron diversos "espacios de confluencia" (p. 223) que resultaron determinantes para comprender qué representaciones del gaucho emergieron y se construyeron en esas interacciones.

Los centros tradicionalistas tuvieron un rol fundamental en el desarrollo de esas interacciones. A fin de reconstruir esa trama, Casas centró su atención en los archivos de un puñado de centros tradicionalistas bonaerenses a los que denominó centros madre: La agrupación "Las Bases" de la ciudad de La Plata cuyos orígenes se remontan a fines de los años veinte, el Circulo Criollo "El Rodeo", que se fundó en la localidad de Santos Lugares en 1939, la agrupación tradicionalista "El Ceibo" de la ciudad de Buenos Aires, de la misma época, y el Círculo Criollo "Martín Fierro", fundado en localidad de Jáuregui en 1945. A partir de publicaciones propias, correspondencia, muestras fotográficas y representaciones iconográficas recompuso el entramado social, amplio y diverso que se consolidó desde esos espacios. Con ese punto de partida, construyó un dialogo entre documentos, publicaciones, imágenes, audios, revistas de interés general, boletines académicos, periódicos de tirada masiva, diarios locales, declamaciones públicas, discursos, libros y ensayos, a fin de indagar formas de circulación, voces disidentes y repercusiones del resurgimiento gauchesco hacia la década del treinta, y en tiempo posterior.

A partir de los archivos de los centros tradicionalistas reconstruyó la trama de espacios de convergencia mayor donde esos vínculos se materializaron. Casas afirma que:

La expansión de la fiesta de la tradición no solo propiciaba un punto de encuentro con representantes católicos, militares y escolares, además propagaba la narrativa del gaucho como símbolo de la argentinidad. La efeméride instituida fue la fecha por antonomasia para exaltar la figura del gaucho, que se interpretaba católico, soldado, y, por sobre todas las cosas, patriota. Allí, 
los que se caracterizaban de gauchos, y los que se distanciaban de esos mecanismos, se entrelazaban para unificar el discurso en pos de la "tradición argentina" (p. 261).

Otro espacio importante donde convergieron distintas instituciones y sectores de la sociedad civil que abonaron articular sentidos en torno al gaucho fueron las peregrinaciones a la Virgen de Lujan desde octubre de 1945. Casas afirma que:

\begin{abstract}
La evolución de las peregrinaciones gauchas -junto con otras festividades alrededor de la Virgen- generó ámbitos de convergencia entre representantes de distintas instituciones. Las delegaciones escolares, los sacerdotes que se involucraban en la organización y desarrollo, los socios de las agrupaciones tradicionalistas y los militares que se integraban a los desfiles constituían un escenario que se reproducía en las fiestas criollas, fomentadas especialmente para exaltar la tradición argentina. Los integrantes de las Fuerzas Armadas no solo fueron complementos esporádicos de las caravanas que desfilaban, también intervinieron como miembros de los centros tradicionalistas contribuyendo, en tanto socios o colaboradores, a la potenciación de esas experiencias (p. 235).
\end{abstract}

Estos elementos permiten ver los modos en que se construyeron niveles de consenso en torno al gaucho. Casas expone la manera en que el debate en relación a la oficialización del día de la tradición o la pertinencia de una estatua al gaucho no sufrieron resistencias de base sobre su legitimidad, sino que las diferencias que distintos sectores políticos pudieron tener en esta materia respondieron a interpretaciones de sentido en torno a las representaciones que cada cual construyó en torno de sí. Se tejió en el propio proceso histórico un consenso por el cual nadie guarda dudas respecto de la figura del gaucho como expresión de argentinidad, y en el que las disputas o tensiones que pudieran surgir nacen ante la pregunta de qué argentinidad, qué Ejército, qué catolicismo se pretende. En una respuesta, a mi criterio tributaria de la pregunta por la función desarrollada por Prieto en El discurso criollista, Casas muestra que el gaucho fue argentino para expandir el mensaje del evangelio y promover la identificación católica con la nación; fomentar la disciplina militar y la abnegación patriótica de los miembros de las fuerzas armadas; transmitir pedagógicamente los valores del estudio y la convivencia social a los alumnos escolares, y consolidar vínculos alrededor de su figura que propagarían el tradicionalismo por distintos canales de difusión. Así, "las metamorfosis del gaucho" fueron variadas pero cada perspectiva para pensar su figura conllevó el componente patriótico como valor incorruptible. Un piso común a todos estos usos fue la concepción del gaucho como símbolo de la argentinidad y del patriotismo, pero cada construcción, reconstrucción y difusión de una nueva interpretación respondió a necesidades coyunturales distintas. En ese sentido, también la marginalidad a la que fueron condenados sus detractores da cuenta de los niveles de consenso que se construyeron en torno al gaucho.

Vale subrayar que el investigador reconoció en todo este derrotero básicamente dos canales significativos de reivindicación de la tradición gauchesca: por un lado, a través de los festejos y las conmemoraciones con prácticas hípicas, un acento puesto en las vestimentas, la comida criolla, etc.; y por otro, en el ámbito de las letras, con una celebración basada en recitados, demostraciones musicales y argumentaciones fuertes sobre el protagonismo gaucho en la historia de la patria. El potencial de los festejos del día de la tradición y los que lo siguieron consistió en buena medida en haber habilitado la confluencia de ambas perspectivas poniendo a traccionar el engranaje tradicionalista, codo con codo, tanto al gaucho como al escritor .

Para quienes estamos preocupados por los debates en torno a la nación y los usos del pasado, el trabajo de Matías E. Casas es una buena noticia. Lo simbólico y lo arquetípico resulta un punto de entrada sumamente fértil para pensar estos problemas, ya que nos permiten identificar niveles de circulación entre distintos ámbitos, con intereses en juego muchas veces disímiles. Prestarle atención a los usos de "algo" nos echa luz sobre dimensiones que pueden ser opacas a una entrada lineal por vía del discurso o de las prácticas. Asimismo, porque identificar texturas y elementos que nos permitan pensar la historia de los sentidos de las cosas, por lo tanto su movimiento, siempre nos dice algo de una época, de una coyuntura, y de sus cambios 